\title{
LA NECESIDAD DE FIJAR LAS INCOMPATIBILIDADES DE LAS INSTITUCIONES ARBITRALES EN ESPAÑA
}

\author{
Ana Belén Álvarez Fernández
}

\begin{abstract}
RESUMEN
En este artículo se realiza un estudio sobre el procedimiento arbitral administrado por asociaciones y entidades sin ánimo de lucro. El tema clave del mismo versa sobre la garantía de imparcialidad que estas instituciones deben tener para que toda persona alcance una verdadera tutela, puesto que existen instituciones arbitrales en España que se posicionan a favor de una parte (la más fuerte económicamente), para administrarles los conflictos que les surjan en sus relaciones jurídicas: con el evidente resultado a su favor. Se propone como solución a este problema de inseguridad arbitral: la creación de normas que sancionen este tipo de comporta-
\end{abstract}

Becaria de Investigación Erasmus de la UAL, con proyecto de investigación: El control del Estado sobre las instituciones privadas: referencia a la protección del consumidor, con el visto bueno para postular el proyecto en la tesis doctoral con mención europea, Lisboa, 2011. Becaria del Instituto de Investigaciones Jurídica de la UNAM, en el que desarrollo como proyecto de investigación La independencia de la PROFECO a la hora de administrar procedimientos arbitrales en materia de consumo, México, 2010. Estudios de Doctorado en Derecho Procesal Internacional (Trabajo de Grado: "Las Instituciones Privadas y la Garantía de la Imparcialidad en los Procedimientos Arbitrales", Facultad de Derecho de la Universidad de Salamanca, España, iniciado en 2008 y cursando el mismo en la actualidad. Master en Asesoría Fiscal, Tributación y Contabilidad de empresas, realizado en el Instituto Superior de Derecho y Empresa (ISDE), 2007. Curso Extraordinario de Formación Continua para la Formación de Asesores Jurídicos de Consumo, realizado en la Universidad de Salamanca, 2006. Licenciada en Derecho por la Universidad de Salamanca.

En la actualidad, Juez de Paz sustituto en España. Responsable del departamento de RRHH de la Asociación de empresarios de transporte (ASETRANSPO) 2011. Asesora Jurídica de ASETRANSPO, 2010. Miembro del Departamento Jurídico de la empresa multinacional MRS Grupo de empresas, 2009. Técnico en RRHH de la mercantil MRS Grupo de empresas, 2007. Profesora de Derecho Internacional Privado en la Academia Aula Siglo XXI en España. Técnico de Consumo en la Oficina Municipal pública de Consumo de Salamanca, 2006. 
mientos, limiten las funciones de estas instituciones y establezcan un régimen de incompatibilidades.

Palabras clave: Arbitraje, instituciones arbitrales, consumidores y usuarios, independencia e imparcialidad.

\begin{abstract}
This article is about the arbitration procedure administered by associations and nonprofit entities. The key issue has to be with the guarantee of impartiality that these institutions should take to reach a real protection of people's interests. In Spain, arbitral institutions are positioned in favor of one party (the strongest economically) to administer the conflicts that arise in their relationships: with the obvious result in their favor. That's the reason why we propose as a solution to this problem of insecurity arbitration the creation of rules that penalize such behavior, limit the functions of these institutions and establish a system of incompatibilities.
\end{abstract}

Key words: Arbitration, arbitral institutions, consumers and users, independence and impartiality.

\title{
1. DE LAS INSTITUCIONES ARBITRALES (IIAA)
}

\subsection{Origen de las instituciones arbitrales}

En la legislación española existen dos formas de administrar arbitraje: el arbitraje Ad Hoc y el arbitraje institucional. En el primero, son las propias partes las que designan al árbitro; mientras que en el segundo, las partes se someten a una institución arbitral (en adelante IA) que es la encargada tanto de administrar el arbitraje como, dependiendo de la voluntad de esas partes, de nombrar al árbitro. A estas dos clasificaciones debemos añadir una tercera: arbitraje mixto, que a pesar de ser un arbitraje institucional, la propia institución les encomienda a las partes y al árbitro (o árbitros) ponerse de acuerdo para llevar a cabo el procedimiento arbitral $\mathrm{y}$, por consiguiente, las instituciones arbitrales (en adelante IIAA) ven reducidas sus funciones ${ }^{1}$.

1 Un ejemplo de este arbitraje mixto es el denominado "procedimiento simplificado" en el Reglamento del Tribunal Arbitral de Barcelona, concretamente en su artículo 14 a): "Procedimiento Simplificado. Consiste en instruir a las partes para que contacten directamente con el árbitro con la finalidad de impulsar y determinar entre ellos el procedimiento arbitral." Desconocemos la utilidad que este tipo de arbitrajes haya tenido en la práctica ya que si las partes pueden directamente elegir un árbitro y establecer el procedimiento a seguir ( $A d H o c$ ), no elegirían someterse a un arbitraje institucional. Además, siguiendo con el ejemplo expuesto del Tribunal Arbitral de Barcelona, es la propia IA o, el propio Tribunal, como se dice en el Reglamento, el que decide el tipo de procedimiento, pudiendo encontrarse las partes (sin quererlo) con que tienen que impulsar y determinar ellas mismas el procedimiento arbitral. 
Dejando a un lado el arbitraje ad hoc y centrándonos en el arbitraje institucional, también llamado: corporativo o administrado², hay que esperar a la Ley de 1988 para su reconocimiento en la legislación española ${ }^{3}$, pues en la Ley de Arbitraje de 1953 no se admitía dicha posibilidad. Bien es cierto, que en el Real Decreto 1094/ 1981, de 22 de mayo, se establecía que las Cámaras Oficiales de Comercio, Industria y Navegación podían realizar arbitrajes entre personas físicas y jurídicas de distintos Estados debido al auge que aquel momento estaba experimentando el comercio internacional ${ }^{4}$.

La Ley Modelo de la CNUDMI sobre Arbitraje Comercial Internacional, aprobada por la Comisión de las Naciones Unidas para el Derecho Mercantil Internacional el 21 de junio de 1985, se refería también al arbitraje institucional ${ }^{5}$. Pero en España, tenemos que esperar hasta el 26 de marzo de 2004, fecha en la que entró en vigor la ley 60/2003, de 23 de diciembre, de Arbitraje, que incorpora en su artículo 14 la denominación de "Arbitraje Institucional", para referirse tanto a las corporaciones de derecho público ${ }^{6}$ como a las asociaciones y entidades sin ánimo de lucro y, encomendándoles también, la administración del arbitraje y la designación de árbitros. A su vez establece los mismos principios que recogía la legislación anterior englo-

2 ROCA MARTÍNEZ, J. M., Arbitraje e Instituciones Arbitrales, editorial Bosch, Barcelona, 1992, p. 174: "... arbitraje administrado utilizada por influencia de la terminología anglosajona (administered arbitration)..."

3 Art. 9.2 de la Ley 36/1988 de 5 de diciembre, de arbitraje: “2. Las partes podrán deferir a un tercero, ya sea persona física o jurídica, la designación de los árbitros.”

4 Exposición de Motivos del Real Decreto 1094/ 1981, de 22 de mayo sobre realización por el Consejo Superior de las Cámaras Oficiales de Comercio, Industria y Navegación de arbitraje comercial internacional: "El creciente desarrollo del comercio internacional comporta la utilización del arbitraje como eficaz instrumento de solución de conflictos en la diaria aplicación e interpretación de los contratos comerciales. El incremento de las relaciones comerciales internacionales, en particular en el área iberoamericana, y la inexistencia de adecuados servicios de arbitraje comercial internacional en nuestro país, determina que la utilización de la técnica arbitral por empresarios y comerciantes de la citada área se efectúe con referencia a instituciones de otro contexto cultural e idiomático, con el efecto negativo que ello representa para España y la pérdida que para nuestro país significa la ruptura de las vinculaciones con los citados países en materia de tan creciente interés común.

A fin de subsanar aquellos inconvenientes y favorecer el arbitraje comercial internacional en nuestro país como servicio a empresarios y comerciantes de cualquier nación, pero en particular iberoamericanos, el presente Real Decreto habilita al Consejo Superior de Cámaras Oficiales de Comercio, Industria y Navegación para que cree el oportuno servicio a fin de facilitar este tipo de arbitraje en España, y ello sin perjuicio de lo que en su día establezca la nueva Ley de Arbitraje, en elaboración."

5 Art. 2.a) de Ley Modelo sobre Arbitraje Comercial Internacional de la CNUDMI, "a) "arbitraje" significa cualquier arbitraje con independencia de que sea o no una institución arbitral permanente la que haya de ejercitarlo."

6 A las que se ya refería el Real Decreto 1094/ 1981, de 22 de mayo pero únicamente a las Cámaras Oficiales de Comercio, Industria y Navegación y sólo al arbitraje comercial internacional. 
bándose en el principio de igualdad ${ }^{7}$, aunque es en el título del artículo de la Ley de Arbitraje 60/2003, donde mencionan también el principio de audiencia y el de contradicción. Éste mismo es recogido en la última modificación de la ley 11/2011, de 20 de mayo, de reforma de la ley 60/2003, de 23 de diciembre, de Arbitraje y de regulación del arbitraje institucional en la Administración General del Estado (en adelante LA).

Ahora bien, desde la primera regulación hasta la vigente, el pilar de la IA es la autonomía de la voluntad de las partes porque constituye la esencia y el fundamento de dicha institución, como así lo reconocen, entre otras las SSTC n 174/1995 y $75 / 1996^{8}$.

Art. 24 de la LA: "Principios de igualdad, audiencia y contradicción. 1. Deberá tratarse a las partes con igualdad y darse a cada una de ellas suficiente oportunidad de hacer valer sus derechos. 2. Los árbitros, las partes y las instituciones arbitrales, en su caso, están obligadas a guardar la confidencialidad de las informaciones que conozcan a través de las actuaciones arbitrales."

8 Sentencia del Tribunal Constitucional № 75/1996, de 30 de abril, cuando expresa en su fundamento de derecho segundo: "Desde esta perspectiva, la demanda ha de ser estimada. En efecto, la Sentencia del Pleno de este Tribunal 174/1995 ha declarado la inconstitucionalidad y consiguiente nulidad del art. 38.2, párrafo primero de la L.O.T.T. En ella, el Tribunal Constitucional se enfrentó al problema planteado, coincidente con el que aquí hemos de responder, acerca de «si resulta conforme a la Constitución, concretamente con sus arts. 24.1 y 117.3 C.E., un precepto que establece un sistema de arbitraje institucional e imperativo, en virtud del cual el acceso a la jurisdicción queda condicionado al consentimiento expreso, formalizado en un pacto, de todas y cada una de las partes implicadas en una controversia» (fundamento jurídico 3.). Ante ello, se declaró que «la autonomía de la voluntad de las partes -de todas las partes-constituye la esencia y el fundamento de la institución arbitral, por cuanto que el arbitraje conlleva la exclusión de la vía judicial. Por tanto resulta contrario a la Constitución que la Ley suprima o prescinda de la voluntad de una de las partes para someter la controversia al arbitraje de la Junta que es lo que hace el párrafo primero del art. 38.2. La primera nota del derecho a la tutela consiste en la libre facultad que tiene el demandante para incoar el proceso y someter al demandado a los efectos del mismo. Quebranta, por tanto, la esencia misma de la tutela judicial tener que contar con el consentimiento de la parte contraria para ejercer ante un órgano judicial una pretensión frente a ella» (fundamento jurídico 3.). Y esto, que está dicho preferentemente desde la perspectiva del demandante, es igualmente aplicable al demandado, en cuanto que, salvo que así lo haya aceptado voluntariamente, no se le puede impedir que sea precisamente un órgano judicial quien conozca de las pretensiones que formule en orden a su defensa, vulnerándose de otra manera su derecho a la tutela judicial efectiva.

Esta conclusión no se desvirtúa, por otra parte, por la posibilidad de un ulterior recurso de nulidad frente al Laudo, previsto en el art. 45 de la Ley de Arbitraje, que la parte intentó y fue desestimado por la Sentencia recurrida, pues, como también declaró la referida STC 174/1995, ese control excluye las cuestiones de fondo, ya que «al estar tasadas las causas de revisión previstas en el citado art. 45, y limitarse éstas a las garantías formales sin poderse pronunciar el órgano judicial sobre el fondo del asunto, nos hallamos frente a un juicio externo (STC 43/1988 y Sentencias del Tribunal Supremo que en ella se citan) que, como tal, resulta insuficiente para entender que el control judicial así concebido cubre el derecho a obtener la tutela judicial efectiva que consagra el art. 24.1 C.E.» (fundamento jurídico $3^{\circ}$ )." 
Pero ¿qué implica administrar un arbitraje? Esta función de administración es la tendente a realizar los actos de gestión necesarios para que el arbitraje se lleve a cabo de una forma eficaz ${ }^{9}$. Las IIAA se limitarían a facilitar los mecanismos y medios necesarios para que se desarrolle el arbitraje y los árbitros puedan realizar su actividad. A su vez, la actuación de las mismas se caracterizaría porque entre las funciones arbitrales que desempeñan no se incluye la decisión o resolución de la controversia ${ }^{10}$. Por ello, el centro arbitral debe tener la confianza de las partes y respetar así los principios esenciales de audiencia, contradicción e igualdad entre las partes.

En el arbitraje institucional la relación de confianza no se traslada a la figura del árbitro, sino que se traslada hacia la IA y se busca con ello una mayor estabilidad en el desarrollo del procedimiento arbitral ${ }^{11}$. Las partes confían en la profesionalidad de tales instituciones y éstas, a su vez, deben garantizar la puesta a disposición de los medios necesarios para el desarrollo del arbitraje, conforme a los términos en que se les haya encomendado intervenir y conforme a sus normas reguladoras. Por ello, la potenciación de esta modalidad arbitral requiere que las IIAA se vayan ganando progresivamente la confianza de quienes puedan encomendarles la administración del arbitraje. Para ello, será necesario que día a día adquieran prestigio y se tome conciencia de que efectivamente su actuación reporta ventajas para el desarrollo del procedimiento arbitral ${ }^{12}$.

La intervención de IIAA permanentes es ventajosa para las partes, les elimina la carga de establecer caso por caso unos árbitros, un procedimiento y unos plazos ${ }^{13}$, y porque es garantía de solvencia e imparcialidad la previa existencia de una organización que respalde rigurosos criterios jurídicos y éticos con una lista de árbitros apropiados a cada contienda, con un procedimiento objetivamente reglamentado por la propia IA $^{14}$.

9 MUNNÉ CATARINA, F., La Administración del Arbitraje, ed. Aranzadi, España, 2002, p. 54 y añade: "Así, cuando se administra un arbitraje no se manifiesta un conflicto de intereses entre las partes compromitentes, sino el interés común de las mismas en aquella administración eficaz."

10 RAMOS MÉNDEZ, F., Derecho Procesal Civil T II, cuarta ed. Bosch, Barcelona, 1990, p. 1268.

11 CREMADES, B. M., "El Arbitraje en el Siglo XXI", ed. La Ley: Revista Jurídica, doctrina, jurisprudencia y bibliografía, No 4, España, 1990, p. 1184 y ss.

12 ROCA MARTÍNEZ, J. M., Arbitraje e Instituciones Arbitrales, ed. Bosch, Barcelona, 1992, p. 178.

13 Ventaja que quizá no tomo excesivamente en cuenta el Tribunal Arbitral de Barcelona a la hora de elaborar su procedimiento simplificado.

14 CHILLÓN MEDINA y MERINO MERCHÁN, Tratado de Arbitraje privado interno e internacional, ed. Civitas, Madrid, 1991, pp. 87 y ss. 


\section{2 ¿Quiénes pueden ser instituciones arbitrales?}

La LA establece ${ }^{15}$, de forma similar a la legislación anterior, que podemos considerar como IIAA a las siguientes:

Corporaciones de derecho público, es decir, aquellas que tienen personalidad jurídica propia y plena capacidad de obrar para cumplir sus fines, con una base asociativa privada por lo que cumplen fines públicos y privados.

Pero no pueden ser consideradas instituciones arbitrales todas las corporaciones de derecho público (Comunidades de Usuarios de Aguas Públicas, Comunidades de Regantes, CORES, etc) sino únicamente aquellas en las que incluyan en sus normas integradoras la administración del arbitraje.

Así, podemos incluir en esta clasificación como instituciones arbitrales de corporación de derecho público: los Colegios Profesionales, las Cámaras de Comercio, industria y navegación, las Cámaras Agrarias, y todas aquellas en las cuales se especifique en su regulación interna las funciones de administración arbitral. La ley incluye de forma explícita al Tribunal de Defensa de la Competencia como institución arbitral.

Asociaciones y entidades sin ánimo de lucro ${ }^{16}$ en cuyos estatutos se prevean funciones arbitrales. La condición que se establece para que puedan administrar los procedimientos arbitrajes es que en sus estatutos se prevea esa función. Este interés por el legislador en remarcar la condición "sin ánimo de lucro" no convence a LORCA NAVARRETE que más bien lo critica cuando dice:

“La opción del artículo 14.1. b) LA es criticable. Es una opción legislativa. Pero nada más. Y sin duda, por la sola circunstancia de ser una opción legislativa no es determinante para adoptar una opción contraria que admita el carácter lucrativo del ámbito societario que administra el arbitraje. Incluso la

15 En su Art 14 de la LA: "Arbitraje institucional.

1. Las partes podrán encomendar la administración del arbitraje y la designación de árbitros a: Corporaciones de Derecho público y Entidades públicas que puedan desempeñar funciones arbitrales, según sus normas reguladoras.

Asociaciones y entidades sin ánimo de lucro en cuyos estatutos se prevean funciones arbitrales.

2. Las instituciones arbitrales ejercerán sus funciones conforme a sus propios reglamentos.

3. Las instituciones arbitrales velarán por el cumplimiento de las condiciones de capacidad de los árbitros y por la transparencia en su designación, así como su independencia."

16 LETE ACHIRICA, J., "Artículo 14 Arbitraje Institucional”, en AA.VV, Comentarios Prácticos a la Ley de Arbitraje, ed. Lex Nova, Valladolid, 2004, p. 256: "...el hecho de que figure en el mismo apartado que las asociaciones, de lo que se desprende que tampoco hubiera sido necesaria utilizar la expresión "sin ánimo de lucro", dada la identificación necesaria que debe existir entre asociación y fin no lucrativo." Además, estas asociaciones y entidades se constituirán según lo previsto en la Ley 191/1964 de asociaciones y deberán inscribirse como tales en el registro provincial de asociaciones o en el nacional." 
opción a favor de la proyección lucrativa del ámbito societario que administra el arbitraje debería ser operativa en la práctica de la institucionalización del arbitraje por cuanto es un elemento que se integra en el principio de autonomía de la voluntad de las partes en el momento en que suscriben el convenio arbitral que les permitiría optar por una vía societaria mercantilizada"17.

En mi opinión, el que no haya ánimo de lucro es decisivo para garantizar que no se realice por las IIAA, por ejemplo, un posicionamiento a favor de una de las partes (concretamente la más fuerte, económicamente hablando) con el fin de buscar "clientes" fuertes que dejen ventajas económicas a la IA. De hecho, estas situaciones, por desgracia, ya se dan a pesar de que el legislador defiende la carencia de ánimo de lucro... si llega a permitirla... Además, una IA que busque lucrarse debería apartarse de administrar y organizar procedimientos arbitrales y dedicarse a otras actividades lucrativas y permitidas en nuestra legislación. Hay que recordar que el arbitraje nace como un medio alternativo de resolución de conflictos más rápido y económico en comparación con la vía judicial. Esta cuestión la analizaremos en el capítulo siguiente.

Como ejemplo de asociaciones y entidades sin ánimo de lucro pueden citarse la Asociación Comunitaria de Arbitraje y Mediación, la Asociación Europea de Arbitraje de Derecho y Equidad, Corte Española de Arbitraje, etc.

Lo que el legislador busca es que tanto las corporaciones como las asociaciones y entidades sin ánimo de lucro no se constituyan para cada procedimiento arbitral que tengan que organizar o administrar, sino que estas IIAA tengan un carácter permanente $^{18}$. Ahora bien, estas instituciones pueden tener únicamente funciones arbitrales o, tener además de estas funciones otras dentro de su finalidad empresarial $^{19}$. A su vez, las IIAA pueden ceñirse al ámbito nacional o, por el contrario pueden establecer en sus reglamentos internos la posibilidad de administrar arbitrajes internacionales con la correspondiente regulación de su procedimiento.

La consecuencia de la amplitud del legislador para facilitar la creación de diversas IIAA bajo el epígrafe de asociaciones y entidades sin ánimo de lucro, contribuyó a que muchas optasen por la gestión y administración del arbitraje como actividad

17 LORCA NAVARreTE, A.M., Comentarios a la Nueva Ley de Arbitraje 60/2003 de 23 de diciembre, ed. Instituto Vasco de Derecho Procesal, San Sebastián, 2004, p. 133.

18 MUNNÉ CATARINA, F., La Administración del Arbitraje. Instituciones Arbitrales y Procedimiento Prearbitral, ed. Aranzadi, Navarra, 2002, p. 32 en la cual señala: "Esta habituabilidad implica que, en el desarrollo de su actividad, pueda exigírseles una profesionalidad y, sobre todo, un conocimiento del Derecho adjetivo aplicable al arbitraje, es decir, la legislación del arbitraje que corresponda y su propio reglamento junto con los principios generales del derecho, la costumbre y la jurisprudencia que sean de aplicación."

19 CHILLÓN MEDINA, J.M. y MERINO MERCHÁN, J.F., Tratado de Arbitraje Privado Interno e Internacional, ed. Civitas, Madrid, 1991, p. 542 que son clasificadas como instituciones de carácter semipúblico. 
o la incluyesen como una de sus funciones. Así, la consecuencia de la proliferación de las IIAA en los últimos años hace que cada una de ellas busque vías para poder mantenerse en el mercado, puesto que, con relativa frecuencia, nos encontramos ante instituciones que sólo existen en el papel o que por su escasa actividad no cumplen otra función arbitral que la de ser un mero buzón de correos ${ }^{20}$ y que por su no reconocimiento o su falta de profesionalidad necesitan de otras funciones añadidas con el fin de que desemboquen en potenciar o incentivar la administración del arbitraje en su centro, cuestión ésta que analizaremos más adelante.

\subsection{Evolución}

Una vez que en las entidades enumeradas anteriormente se asume en sus estatutos o en sus normas reguladoras la actividad de administrar y organizar arbitrajes, estamos ante IIAA. A su vez, éstas deben elaborar un reglamento interno ${ }^{21}$ que regule dichas labores de administración arbitral (designar a los árbitros, procedimiento arbitral, plazos...), según lo encomendado por las partes, conducentes a controlar y vigilar el correcto desarrollo del arbitraje $\mathrm{e}^{22}$. Entre las funciones de administración de estas Instituciones no se encuentra implícita la de decidir sobre el conflicto ${ }^{23}$, ya sea directamente, cuando la Institución realiza actos conducentes a posicionarse a favor de una de las partes en conflicto, otorgándole así una ventaja en la defensa de sus intereses. O ya sea indirectamente, es decir, cuando la Institución tiene encomendada la designación de los árbitros y nombra para tal tarea a personas influidas por ésta para que resuelvan la controversia según el criterio seguido por la propia Institución.

Las IIAA no pueden ni decidir en el asunto sometido a arbitraje ni pueden arbitrar el mismo de forma alguna, únicamente deben limitarse a organizar y administrar el procedimiento arbitral. En la práctica del día a día del arbitraje institucional, se plantean casos en los cuales algunas IIAA toman partido en la resolución del conflicto. Esta práctica es fruto de la evolución del sistema arbitral debido al gran elenco de Instituciones que podemos encontrarnos y, para que se puedan mantener todas en el mercado se busca marcar una diferencia tal entre unas y otras, se cae en el error de posicionarse a favor de una de las partes para conseguir mayores "clientes" que de forma voluntaria ${ }^{24}$ se sometan a su IA para solucionar todos aquellos

20 CREMADES, B.M., "El Arbitraje en el Siglo XXI”, ed. La Ley: Revista Jurídica, doctrina, jurisprudencia y bibliografía, No 4, España, 1990, p. 1189.

$21 \quad$ Artículo 14.2 de la LA 2003: "Las Instituciones arbitrales ejercerán sus funciones conforme a sus propios Reglamentos."

22 ROCA MARTÍNEZ, J. M., Arbitraje e Instituciones Arbitrales, ed. Bosch, Barcelona, 1992, p. 220.

23 RAMOS MÉNDEZ, F., Derecho Procesal Civil T.II, ed. Bosch, Barcelona, 1986, p. 1268.

24 Tras ofrecer una serie de ventajas entre otras, económicas. 
conflictos que les surjan. Eso sí, una de las partes que se somete a esta Institución sabe que va a gozar de una posición superior para la defensa de sus intereses dentro del procedimiento arbitral, mientras que la otra parte, desconocedora de este desequilibrio acepta someterse a esa Institución ${ }^{25}$. La parte desfavorecida se da cuenta de la desigualdad que existe entre ambas partes cuando ya se encuentra avanzado el procedimiento arbitral o, en la mayoría de los casos, cuando se dicta el laudo ${ }^{26}$.

¿Qué problemas genera esta actuación de las IIAA? Claramente, las instituciones arbitrales que realizan estas prácticas no gozan de la objetividad necesaria para poder seguir administrando procedimientos arbitrales, vulneran el derecho al debido proceso ${ }^{27}$ y no observan el principio de la buena fe procesal ${ }^{28}$. Es cierto que en la anterior legislación de arbitraje se preveía una remisión al texto procesal y, en la actual legislación se omite tal remisión siendo característica de la norma de arbitraje la voluntad de las partes y, concretamente, de la fe ciega que se otorga a los reglamentos de las IIAA a las que se sometan las partes. Una vez dicho esto, no es propio pensar que no debemos tener en cuenta aquellos principios procesales consagrados en nuestra legislación ordinaria a la hora de ver un procedimiento arbitral, tampoco debemos dar la espalda a aspectos ya estudiados y analizados porque seguro que ya resolvieron problemas que se pueden plantear en los procedimientos arbitrales, y, que sin duda, serán de gran ayuda.

La consecuencia inmediata de esta pérdida de derechos, aparte del menoscabo producido a la parte afectada, sería el aumento de la desconfianza hacia el sistema arbitral y la consiguiente huída del mismo ${ }^{29}$. Se pasaría de una relación de confianza depositada en una determinada institución, al negocio que puede suponer, para algunas IIAA, el someterse a un centro arbitral. Se desplazaría la relación de confianza en un tercero (en este caso una IA) por el negocio o ventaja que puede suponer a una de las partes el someter la controversia en determinado centro arbitral; todo ello debido al fin lucrativo que se presenta a la hora de que se administre el arbitraje

25 Salvo que nos encontremos ante aquellos contratos denominados contratos de adhesión en los cuales no hay una voluntad real de la parte.

26 Quedándole la opción de presentar solicitud de anulación de laudo arbitral.

27 Artículo 24. 2 de la Constitución Española: "Así mismo, todos tienen derecho al juez ordinario predeterminado por la ley, a la defensa y a la asistencia de letrado, a ser informados de la acusación formulada contra ellos, a un proceso público sin dilaciones indebidas y con todas las garantías, a utilizar los medios de prueba pertinentes para su defensa, a no declarar contra sí mismos, a no confesarse culpables y a la presunción de inocencia."

28 DE LA OLIVA SANTOS, A. y DÍEZ-PICAZO GIMÉNEZ, I., Derecho Procesal Civil. El Proceso de Declaración. Conforme a la ley 1/2000 de 7 de enero, de Enjuiciamiento Civil, ed. Centro de Estudios Ramón Areces, 2000, Madrid, p. 7: “No obstante, en aspectos concretos, la LEC mejora o completa la regulación del arbitraje."

29 Para LINDNER, A., en su artículo "Arbitraje Internacional”, publicado en la Revista Economist E Jurist, No 122, 2008, p. 35 señala: "La ventaja principal del arbitraje institucional es que el nombramiento de los árbitros está en manos de expertos (...).” Pero no siempre esto es así. 
por un centro al que se le paga una cuota como asociado o colaborador, el cual señala ventajas económicas a esa parte adscrita al mismo. Y esas ventajas suponen un desequilibrio entre las partes a la hora de iniciar el arbitraje en esa institución, comportamiento del que nos apartamos.

\subsection{En la actualidad}

En el día a día de la mayoría de las instituciones arbitrales englobadas dentro de las asociaciones y entidades sin ánimo de $\operatorname{lucro}^{30}$, se busca una publicidad competitiva de las mismas. Así, se editan revistas por estas instituciones, se realizan seminarios, coloquios, concursos sobre el arbitraje y su fomento. Esta forma de marketing es un método más para promocionar la institución y darle publicidad. Además de estas formas de difusión de las instituciones arbitrales, hay otras prácticas que se llevan a cabo para fomentar la sumisión a determinada institución arbitral que vulneran la garantía de imparcialidad reconocida en nuestra Constitución y con las que no estamos de acuerdo. Por ejemplo: ofrecer un servicio de asesoramiento previo a una de las partes redactando los contratos de las relaciones jurídicas que tenga esa parte asesorada en su ámbito comercial (y evidentemente, incluyendo la cláusula de sumisión a su centro arbitral) para posteriormente administrar los procedimientos arbitrales de las controversias que le surjan a esa parte asesorada (es decir, a un cliente del propio centro arbitral) y nombrar el árbitro para que resuelva la controversia. Es fácil poder adivinar el resultado de ese procedimiento arbitral en el cual no se desfavorecerá al cliente de la institución arbitral, sino a la otra parte, llegando incluso a realizar el centro arbitral, la averiguación de bienes pertinente para que "su cliente y parte" tenga todas las facilidades posibles de hacer valer sus pretensiones y ejecutarlas. Todo un pack que se ofrece a los clientes de esas instituciones como una ventaja para someterse a su centro arbitral. Otra práctica que nos encontramos es la posibilidad de ser hasta socios de estas instituciones, podremos tener voz y voto en sus asambleas, podemos pagar una cuota anual por la que se incluyen unas ventajas económicas en el procedimiento arbitral... y únicamente con la condición de que se sometan las controversias que tenga ese "asociado" a dicha institución arbitral. Y claro, una vez iniciado el procedimiento arbitral ante esa institución nos encontraremos que una de las partes, en principio, va a pagar menos que la otra, que una de las partes es socia de esa institución y por lo tanto tiene una relación previa de amistad o posicionamiento hacia esa parte con la IA, que nombrará al árbitro que a su vez resolverá cualquier controversia que pueda tener ese socio. Por lo que esa relación parcial de uno de los litigantes con la IA puede influir en los que deben decidir la controversia: los árbitros. Debido a esa parcialidad podemos

30 Que en el supuesto de que no se cumpla el requisito "sin ánimo de lucro", sostiene ÁLVAREZ SÁNCHEZ DE MOVELLÁN, P., La Anulación del Laudo Arbitral, ed. Comares, Granada, 1996, p. 196 : "estaremos ante un arbitraje informal, carente del efecto excluyente de la jurisdicción ordinaria y cuyo laudo no tendrá efectos idénticos a la cosa juzgada". 
adivinar el resultado del litigio planteado en ese procedimiento arbitral: se buscará favorecer la pretensión del asociado.

Gisbert Zamora, en un artículo sobre el arbitraje institucional en la LA, daba un voto de confianza a estas instituciones al decir:

“..., esperamos que las instituciones arbitrales sepan aprovechar la oportunidad que esta nueva ley les brinda y hagan de sus reglamentos la norma para que las partes encuentren en el arbitraje institucional la respuesta ágil, sencilla y directa que hoy necesitan ante los conflictos que surgen en las dinámicas relaciones modernas"31.

La realidad, en la práctica de estos años es que las IIAA (concretamente las asociaciones y entidades sin ánimo de lucro) vieron en la administración y organización del arbitraje un negocio suculento que no iban a dejar escapar. En mi opinión, el legislador fue un tanto ingenuo al darle tantas facilidades a estas instituciones para poder intervenir como administradoras de procedimientos arbitrales. Es cierto que el legislador piensa en el arbitraje institucional como una garantía para las partes ${ }^{32}$, pero el problema es que no les establece ni unos límites, ni unas restricciones en sus funciones, ni determina un régimen de incompatibilidades. Como adelantábamos antes, vamos a enumerar ejemplos reales en los que se puede apreciar los medios empleados de publicidad y captación de personas físicas y jurídicas para que se acojan al arbitraje de una determinada institución, la falta de garantías en los procedimientos arbitrales por algunas instituciones y su consecuencia: la obtención de laudos que no se pueden ejecutar por vulnerar esas garantías fundamentales entre las que se encuentra la imparcialidad.

\section{REFERENCIA ESPECIAL AL ARBITRAJE CON CONSUMIDORES}

La defensa de los consumidores se reconoce en el artículo 51 de nuestra Constitución como principio rector de la política social y económica, que los poderes públicos deben garantizar.

En la sentencia del Tribunal de Justicia de la Unión Europea de 9 de septiembre de 2004 se establece lo siguiente:

31 GISBERT ZAMORA, M., “El Arbitraje Institucional en la Ley 60/2003 de 23 de diciembre”, en Revista Derecho de los Negocios, n' 168 , septiembre de 2004, p. 18 y en el cual se plantea: "si está compensada con las suficientes garantías como para crear la confianza y seguridad que requiere la actuación de las instituciones (arbitrales)".

32 DÍEZ CLAVERO, J., “Tendencias del Derecho hacia el arbitraje institucional mercantil”, en Revista crítica de derecho inmobiliario, № 627, 1995, también confía en estas Instituciones arbitrales señalando en la página 552: “(...) tratándose del arbitraje institucional, se incrementan las garantías de los particulares sometidos a él, frente a la posible conducta dolosa o culposa de los árbitros, pues además de que la aceptación supone un deber de cumplimiento fiel del encargo (...)". 
"La distinción que establece en lo que atañe a la regla de interpretación aplicable, entre las acciones que implican a un consumidor individual y las acciones de cesación, que implican a las personas u organizaciones representativas del interés colectivo, se explica por la distinta finalidad de ambos tipos de acciones. En el primer caso, los tribunales u órganos competentes ${ }^{33}$ han de efectuar una apreciación in concreto del carácter abusivo de una cláusula contenida en un contrato ya celebrado, mientras que, en el segundo caso, les incumbe efectuar una apreciación in abstracto del carácter abusivo de una cláusula cuya posible inclusión se prevé en contratos que todavía no se han celebrado. En el primer supuesto, una interpretación favorable al consumidor individualmente afectado beneficia inmediatamente a éste. En el segundo supuesto, en cambio, para obtener con carácter preventivo el resultado más favorable para el conjunto de los consumidores, no procede, en caso de duda, interpretar la cláusula en el sentido de que produce efectos favorables para ellos. De este modo, una interpretación objetiva permite prohibir con mayor frecuencia la utilización de una cláusula oscura o ambigua, lo que tiene como consecuencia una protección más amplia de los consumidores."

En la ley 44/2006 de 29 de diciembre, de Mejora de la Protección de los Consumidores y Usuarios se constata la ineficacia de este aspecto in abstracto en la anterior legislación, la Ley General para la Defensa de los Consumidores y Usuarios, y se quiere prevenir la imposición al consumidor de arbitrajes distintos del Sistema Arbitral de Consumo ${ }^{34}$.

33 Añadiendo nosotros también a los árbitros.

34 Exposición de Motivos VII de la ley 44/2006 de 29 de diciembre de Mejora de la Protección de los Consumidores y Usuarios: ley 44/2006 de 29 de diciembre, de mejora de la protección de los consumidores y usuarios en su E.M. VII "Por otro lado, también se ha constatado la ineficacia del artículo 10.4 de la Ley General para la Defensa de los Consumidores y Usuarios, para prevenir la imposición al consumidor de arbitrajes distintos del Sistema Arbitral de Consumo. Esto justifica la modificación que ahora se realiza, suprimiendo este precepto y reconduciendo, en el artículo 31, los pactos de sumisión al momento en el que el consumidor puede evaluar correctamente el alcance de la decisión que, en la mayor parte de los casos, se ve obligado a adoptar, y que es aquél en el que surge la controversia. Se eleva con ello la protección del usuario ante fórmulas arbitrales no siempre lícitas y se garantiza la no renuncia previa a los derechos reconocidos legalmente. Esta regla se completa con la determinación de la nulidad de los pactos suscritos contraviniéndola, en aplicación de las previsiones de la propia Ley General para la Defensa de los Consumidores y Usuarios sobre la irrenunciabilidad de los derechos reconocidos por la ley al consumidor. La tipificación de su vulneración, como infracción de consumo, se deduce claramente del artículo 34, apartado 11, según la modificación efectuada por esta norma, en el que se califica como tal el incumplimiento de los requisitos, obligaciones o prohibiciones establecidas en esta Ley y disposiciones que la desarrollen.

Se aclara, asimismo, la eficacia de esta previsión en todos los sectores, incluido el de seguros, a cuyo efecto es preciso introducir una ligera modificación en el artículo 61, apartado 3 del Real Decreto Legislativo 6/2004, de 29 de octubre, por el que se aprueba el texto refundido de la Ley de ordenación y supervisión de los seguros privados. 
Así, la Ley General para la Defensa de los Consumidores y Usuarios establece que el momento en el que el consumidor puede evaluar correctamente el alcance de la decisión para someterse al arbitraje privado de una IA es cuando surge la controversia $^{35}$. Y establece como cláusula abusiva la sumisión a arbitrajes distintos del arbitraje de consumo ${ }^{36}$.

El sistema arbitral de consumo se caracteriza, entre otras cosas, por ser un procedimiento sencillo ${ }^{37}$ y porque el órgano arbitral estará compuesto por un represen-

Transcurridos cuatro años desde la entrada en vigor de la Ley 1/2000, de 7 de enero, de Enjuiciamiento Civil, se facilita el ejercicio de las acciones en defensa de los intereses difusos de los consumidores y usuarios, y se da cumplimiento a lo previsto en el artículo 11. 3 de dicha norma. En materia de legitimación procesal, se amplía la concedida al Instituto Nacional del Consumo para el ejercicio de acciones de cesación."

35 Exposición de Motivos II del Real Decreto Legislativo 1/2007, de 16 de noviembre, por el que se aprueba el texto refundido de la Ley General para la Defensa de los Consumidores y Usuarios y otras leyes complementarias: "Conforme a la regulación adoptada, los pactos de sumisión al arbitraje se conducen al momento en el que el consumidor puede evaluar correctamente el alcance de la decisión que, en la mayor parte de los casos, se ve obligado a adoptar, y que es aquél en el que surge la controversia. Se eleva con ello la protección del usuario ante fórmulas arbitrales no siempre lícitas y se garantiza la no renuncia previa a los derechos reconocidos legalmente. Esta regla se completa con la determinación de la nulidad de los pactos suscritos contraviniéndola, en aplicación de las previsiones de la propia Ley General para la Defensa de los Consumidores y Usuarios sobre la irrenunciabilidad de los derechos reconocidos por la ley al consumidor. La tipificación de su vulneración, como infracción de consumo, se deduce claramente de la letra $k$ del artículo 49.1 en el que se califica como tal el incumplimiento de los requisitos, obligaciones o prohibiciones establecidas en esta Ley y disposiciones que la desarrollen.

Se incorpora al articulado, asimismo, las precisiones introducidas por la reiterada Ley 44/2006, de 29 de diciembre, sobre la determinación reglamentaria de los supuestos en que podrá interponerse reclamación ante la Junta Arbitral Nacional frente a las resoluciones de las juntas arbitrales territoriales sobre admisión e inadmisión de solicitudes de arbitraje y el establecimiento, asimismo, en la norma reglamentaria, de los supuestos en que actuará un árbitro único en la administración del arbitraje de consumo."

36 Art. 90 de la LGCU: "Cláusulas abusivas sobre competencia y derecho aplicable. Son, asimismo, abusivas las cláusulas que establezcan:

1. La sumisión a arbitrajes distintos del arbitraje de consumo, salvo que se trate de órganos de arbitraje institucionales creados por normas legales para un sector o un supuesto especifico.

2. La previsión de pactos de sumisión expresa a Juez o Tribunal distinto del que corresponda al domicilio del consumidor y usuario, al lugar del cumplimiento de la obligación o aquél en que se encuentre el bien si éste fuera inmueble.

3. La sumisión del contrato a un Derecho extranjero con respecto al lugar donde el consumidor y usuario emita su declaración negocial o donde el empresario desarrolle la actividad dirigida a la promoción de contratos de igual o similar naturaleza."

37 SAN CRISTÓBAL REALES, S., "El Arbitraje de Consumo" en Anuario Jurídico y Económico Escurialense, № 40, 2007, p. 118: "Sus trámites procedimentales son sencillos y accesibles, porque están regidos por los principios de inmediatez, concentración y rapidez, pero sin que por ello dejen de ser exigibles los principios básicos inherentes a todo proceso, de audiencia, contradicción e igualdad entre las partes, por ser estos procesos arbitrales una alternativa a la 
tante de los sectores empresariales y otro de las organizaciones de consumidores y usuarios ${ }^{38}$. Esta elección por la Junta arbitral garantiza la independencia en este tipo de arbitrajes, aunque haya autores, como GUTIÉRREZ SANZ, que no estén de acuerdo ${ }^{39}$. En este sistema arbitral de consumo se garantizan los principios de audiencia, contradicción, igualdad de las partes y gratuidad ${ }^{40}$. Una de las grandes

jurisdicción. En caso de que se vulneren los principios del proceso arbitral se puede utilizar la acción de anulación frente al laudo arbitral para hacerlos valer."

38 Arts. 57 y 58 de LGCU: “Artículo 57. Sistema Arbitral del Consumo.

1. El Sistema Arbitral del Consumo es el sistema extrajudicial de resolución de resolución de conflictos entre los consumidores y usuarios y los empresarios a través del cual, sin formalidades especiales y con carácter vinculante y ejecutivo para ambas partes, se resuelven las reclamaciones de los consumidores y usuarios, siempre que el conflicto no verse sobre intoxicación, lesión o muerte o existan indicios racionales de delito.

2. La organización, gestión y administración del Sistema Arbitral de Consumo y el procedimiento de resolución de los conflictos, se establecerá reglamentariamente por el Gobierno. En dicho reglamento podrá preverse la decisión en equidad, salvo que las partes opten expresamente por el arbitraje de derecho, el procedimiento a través del cual se administrará el arbitraje electrónico, los supuestos en que podrá interponerse una reclamación ante la Junta Arbitral Nacional frente a las resoluciones de las Juntas arbitrales territoriales sobre admisión o inadmisión de las solicitudes de arbitraje y los casos en que actuará un árbitro único en la administración del arbitraje de consumo.

3. Los órganos arbitrales estarán integrados por representantes de los sectores empresariales interesados, de las organizaciones de consumidores y usuarios y de las Administraciones públicas. 4. Los convenios arbitrales con los consumidores distintos del arbitraje de consumo previsto en este artículo, sólo podrán pactarse una vez surgido el conflicto material o controversia entre las partes del contrato, salvo que se trate de la sumisión a órganos de arbitraje institucionales creados por normas legales o reglamentarias para un sector o un supuesto específico.

Los convenios arbitrales pactados contraviniendo lo dispuesto en el párrafo precedente serán nulos.

Artículo 58. Sumisión al Sistema Arbitral del Consumo.

1. La sumisión de las partes al Sistema Arbitral del Consumo será voluntaria y deberá constar expresamente, por escrito, por medios electrónicos o en cualquier otra forma admitida legalmente que permita tener constancia del acuerdo.

2. Quedarán sin efecto los convenios arbitrales y las ofertas públicas de adhesión al arbitraje de consumo formalizados por quienes sean declarados en concurso de acreedores. A tal fin, el auto de declaración de concurso será notificado al órgano a través del cual se hubiere formalizado el convenio y a la Junta Arbitral Nacional, quedando desde ese momento el deudor concursado excluido a todos los efectos del Sistema Arbitral de Consumo."

39 GUTIÉRREZ SANZ, M. R., "La Independencia e Imparcialidad de los árbitros en el arbitraje de consumo", en Estudios sobre Consumo, No 55, 2000, p. 91: "Son precisamente esos representantes de los consumidores y de los empresarios los que pueden plantear problemas. La Junta Arbitral escoge a los árbitros a partir de los propuestos por las propias asociaciones de consumidores y por las organizaciones empresariales, y no queda más remedio que cuestionarnos el grado de independencia de esos árbitros respecto a aquellos organismos que los proponen. Aun sin poner en duda la real soberanía de los vocales, desde luego, el sistema parece un tanto inapropiado para salvaguardar esa independencia que no solo precisa ser real, sino también tener tal apariencia."

40 Art. 41 del Real Decreto 231/2008, de 15 de febrero, por el que se regula el Sistema Arbitral de Consumo: "Principios del procedimiento arbitral de consumo. 
ventajas para el consumidor es que los arbitrajes de consumo son gratuitos ${ }^{41}$, a diferencia de los que ofrecen las IIAA. Y, evidentemente, la mayoría de los consumidores, si pudieran elegir, optarían por este arbitraje que no les ocasionará apenas ningún coste ${ }^{42}$. Por ello, los convenios arbitrales pactados en contra de la legislación establecida en consumo son nulos ${ }^{43}$, pues se establece la imposibilidad de renunciar a los derechos reconocidos por la ley al consumidor ${ }^{44}$.

Esta LA es supletoria a la legislación del arbitraje de consumo ${ }^{45}$, por lo que toda IA, como veíamos en los epígrafes anteriores, que elabore tanto convenios arbitrales como cláusulas de sumisión debe tenerlo presente. Además, esta LA es bastante pobre respecto de la regulación de los límites para las IIAA en materia de consumo ${ }^{46}$, por lo que nos encontramos con cantidad de publicidad ofertada por

1. El procedimiento arbitral de consumo se ajustará a los principios de audiencia, contradicción, igualdad entre las partes y gratuidad.

2. Los árbitros, los mediadores, las partes y quienes presten servicio en las Juntas Arbitrales de Consumo, están obligados a guardar confidencialidad de la información que conozcan en el curso del procedimiento arbitral."

${ }^{41}$ GARCÍA GÓMEZ, R., "El Convenio Arbitral de Consumo. Arbitraje de Consumo y Justicia Material (1)" dentro del libro colectivo: Estudios de Derecho y Obligaciones. Homenaje al profesor Mariano Alonso Pérez, ed. La Ley, Madrid, 2006, p. 790: “Como luego veremos, aun siendo los arbitrajes de consumo naturalmente gratuitos, se podrán imponer costes para los intervinientes en los casos determinados reglamentariamente (práctica de peritajes)."

42 PASARO MÉNDEZ, I., "Arbitraje y Alquiler (II): El arbitraje para resolver conflictos sobre el impago de rentas y desahucio en arrendamientos de viviendas" en Pórtico Legal, diciembre de 2007: "A nadie se le escapa que si surge un conflicto por impago de rentas y/o desahucio, el inquilino que tenga la condición de consumidor, jamás aceptaría el arbitraje privado y menos si se desarrolla en un domicilio distinto al de la vivienda."

43 Artículo 31.4 de la Ley 44/2006 de la LGDCU: "Los convenios arbitrales con los consumidores distintos del arbitraje de consumo previsto en este artículo, sólo podrán pactarse una vez surgido el conflicto material o controversia entre las partes del contrato salvo que se trate de la sumisión a órganos de arbitraje institucionales creados por normas legales o reglamentarias para un sector o un supuesto específico. Los convenios arbitrales pactados contraviniendo lo dispuesto en el párrafo precedente serán nulos."

44 PASARO MÉNDEZ, I., "Arbitraje y Alquiler (II): El arbitraje para resolver conflictos sobre el impago de rentas y desahucio en arrendamientos de viviendas" en Pórtico Legal, diciembre de 2007: "Esta regla se completa con la determinación de la nulidad de los pactos suscritos contraviniéndola, en aplicación de las previsiones de la propia Ley General para la Defensa de los Consumidores y Usuarios sobre la imposibilidad de renunciar a los derechos reconocidos por la ley al consumidor."

45 Disposición Adicional única de la ley 60/2003: "Arbitrajes de consumo. Esta Ley será de aplicación supletoria al arbitraje a que se refiere la Ley 26/1984, de 19 de julio, general de defensa de consumidores y usuarios (derogada), que en sus normas de desarrollo podrá establecer la decisión en equidad, salvo que las partes opten expresamente por el arbitraje en derecho."

46 LA MONEDA DÍAZ, F., "La nueva ley 60/2003, de arbitraje, y su incidencia en el sistema arbitral de consumo", en Revista La Ley, 27 de mayo de 2004, p. 1, "ya es de agradecer que se acuer- 
diversas IIAA en la que se ofrecen procedimientos arbitrales "seguros y garantistas" y en los que una de las partes es un consumidor, sobre todo en materia de arrendamientos urbanos, y que no cumplen con las disposiciones legales que protegen a los consumidores ${ }^{47}$ porque parecen que buscan la sumisión masiva a su centro arbitral con el peligro de olvidarse de la voluntad de las partes ${ }^{48}$ para intentar buscar un interés económico en la IA.

\section{DE LA INDEPENDENCIA Y DE LA IMPARCIALIDAD}

\subsection{En el ámbito judicial}

En el ámbito judicial quedó sólidamente establecida la necesidad de independencia e imparcialidad, aspectos que deben quedar también consolidados en el arbitraje. Veamos qué opina la doctrina, si traslada o no los anteriores conceptos al proceso arbitral. Lorca Navarrete ${ }^{49}$ sostiene que la IA ha de ser independiente pero no se le puede exigir que sea imparcial puesto que no es ella la que dicta el laudo. De forma breve nos referiremos a la independencia y la imparcialidad judicial sabiendo que depende una de la otra ${ }^{50}$.

de la ley del arbitraje de consumo, aunque sea tan tímidamente, y desde luego es reprochable que no lo haya incluido expresamente en el artículo 14 que refiere los arbitrajes institucionales, cuando decenas de miles de reclamaciones anuales avalan el sistema arbitral de consumo como uno de los más eficaces en su tramitación y resolución y más prestigiados entre los consumidores y empresarios"

47 MATEU PROMEIN, Carlos. “¿Las cláusulas de arbitraje en arrendamientos urbanos son válidas?" En: Revista Inmueble a fondo, n 76 noviembre, 2007, p. 42: “También debemos señalar que estas asociaciones de arbitraje privado incurren en publicidad engañosa al señalar que "alquilar ya no es un riesgo", ya que el alquiler siempre implica un riesgo, máxime cuando el inquilino es moroso profesional. En consecuencia, cabe señalar que la única vía válida y legal para resolver el contrato de arrendamiento de vivienda por impago de rentas y/o cantidades asimiladas a las mismas, es acudir a la jurisdicción civil ordinaria, instando el correspondiente juicio civil de desahucio y reclamación de rentas."

48 SAN CRISTÓBAL REALES, S., "El Arbitraje de Consumo", en Anuario Jurídico y Económico Escurialense, № 40, 2007, p. 124: "El arbitraje es un sistema voluntario de resolución de controversias, de modo que, sin la concurrencia de las correspondientes voluntades de las partes de someterse a este sistema, tendrán que acudir a otra vía de resolución de sus conflictos"

49 LORCA NAVARRETE, A.M., “ ¿Tienen que ser las Instituciones Arbitrales Independientes y/o Imparciales?” en Revista Vasca de Derecho Procesal y Arbitraje, Tomo XVIII, Septiembre 2006: "La IA ha de ser independiente cuando administra el arbitraje y designa árbitros para laudar (...) conceptualmente no puede ser imparcial por cuanto esos cometidos de la IA en modo alguno pueden comprometer el resultado final del laudo arbitral en la medida en que quien procede a laudar es el árbitro y no la IA."

50 JIMÉNEZ ASENSIO, R., "Imparcialidad Judicial y Derecho al Juez Imparcial en la Constitución de 1978" en el libro La Imparcialidad Judicial, ed. Consejo General del Poder Judicial, Madrid, 2009, p. 17: "La imparcialidad judicial, como decíamos, está estrechamente vinculada con el principio de independencia. Y, además, con el fin de garantizar ese principio de independencia, 
La independencia judicial debe ser comprendida como la ausencia de subordinación jurídica ${ }^{51}$. Con ello se persigue alcanzar precisamente la sumisión del juez a la ley exclusivamente. Esa ley será interpretada y aplicada por los jueces, pero emanada del legislativo. Siguiendo a Jiménez Asensio ${ }^{52}$ "la Independencia se conectaría con la potestad jurisdiccional, mientras que la imparcialidad habría que predicarla del ejercicio concreto de la función jurisdiccional". La independencia hace referencia al momento constitucional y la imparcialidad al momento procesal ${ }^{53}$.

La independencia judicial es el derecho a ser juzgado por un juez independiente, inamovible, no presionado o coaccionado; un Juez es independiente cuando asume la responsabilidad de sus actos ${ }^{54}$. Así, la independencia hace referencia a cada juez en concreto y a la posición en que se encuentra a la hora de juzgar ${ }^{55}$. La independencia se define entonces como la ausencia de vínculos orgánicos y funcionales entre los jueces y magistrados integrantes del Poder judicial y los restantes poderes del Estado, en tanto la imparcialidad consiste en la necesidad de que, en cada proceso concreto, el juez llamado a fallarlo carezca de cualquier vinculación con el objeto del litigo o con las partes, capaz de conducirlo a mostrar preferencia por alguna de ellas ${ }^{56}$. El tribunal ante el cual se planteen los diversos litigios debe estar constituido de tal manera que dé lugar a una seguridad razonable de su honestidad e imparcialidad ${ }^{57}$.

pero también con la finalidad de evitar la colusión de intereses que pueda estar en la raíz de una tacha de parcialidad del Juez, es como se construye todo el sistema de incompatibilidades judiciales."

51 Esto se relaciona con el principio de inamovilidad.

52 JIMÉNEZ ASENSIO, R., Imparcialidad Judicial y Derecho al Juez Imparcial, ed. Aranzadi, Navarra, 2002, p. 69.

53 CAlvo SÁnCheZ, M. C., Control de la Imparcialidad del Tribunal Constitucional, ed. Atelier, Barcelona, 2009, p. 24.

54 LORCA NAVARRETE, A. M., Manual de Garantías Jurisdiccionales y Procesales del Derecho, ed. Dykinson, Madrid, 1998, p. 144: "La independencia y responsabilidad son dos cualidades que deben concebirse formando una inescindible: el Juez es independiente porque asume la responsabilidad de sus actos y es responsable por ser independiente y para que su independencia no degenere en arbitrariedad."

55 RUIZ MORENO, J. M., "Nombramiento y aceptación de los árbitros. Imparcialidad, Abstención y Recusación" dentro del libro Estudios sobre el arbitraje: los temas clave, ed La Ley, 2008, p. 93: "Habitualmente cuando se alude a la independencia judicial se quiere expresar con esta nota, la ausencia de injerencias en la función jurisdiccional por parte de otros poderes del Estado. No obstante, habría que puntualizar que la independencia más que una cualidad predicable de la organización jurisdiccional en su conjunto-poder judicial-, hace referencia a cada juez en concreto y a la posición en que se encuentra a la hora de juzgar."

56 GUTIÉRREZ SANZ, M. R., "La Independencia e Imparcialidad de los árbitros en el Arbitraje de Consumo", en Estudios sobre consumo, n 55, 2000, p. 90.

57 COUTURE, E. J., Fundamentos del derecho procesal civil, ed. Depalma, Buenos Aires, 1993, p. 150: "Pero ¿qué es una razonable oportunidad de hacer valer el derecho? En términos muy 


\subsection{En los procedimientos arbitrales}

Es aquí donde se plantean disputas acerca de si la IA debe ser imparcial e independiente. La consecuencia de las dudas que puedan surgir al respecto vienen motivadas por el silencio que guarda la LA, aparte de no hacer apenas mención a la institución arbitral: su regulación, límites en su actividad, incompatibilidades, etc., tampoco regula pilares básicos que debe observar la IA como son la independencia y la imparcialidad.

Empezando por la independencia también nos encontramos con autores a favor y en contra. Lorca Navarrete sostiene que "la IA ha de ser independiente cuando administra el arbitraje y designa árbitros para laudar ${ }^{58 " ; ~ y ~ M a t h e u s ~ L o ́ p e z ~}$ afirma que "la existencia de una relación entre el árbitro y la institución arbitral, encargada de la gestión y administración del arbitraje, no debe ser necesariamente un factor descalificante. En tal sentido, dado que son los árbitros quienes juzgan la controversia y no la institución arbitral, que sólo administra el arbitraje, dicha relación no crea por si misma dependencia o parcialidad ${ }^{59}$.

En nuestra opinión, la IA debe ser independiente respecto de las partes, a la hora de administrar el arbitraje entre ellas, como con el árbitro que la propia institución designa. La práctica de algunas IIAA conlleva a que árbitros designados por ellas dicte laudos según las políticas de estas instituciones. Es más, en diversas sentencias se declara probado que el árbitro que se encarga de resolver la controversia es empleado de la institución, y abogado de una de las partes, la más fuerte económicamente. En los dos primeros fundamentos de derecho de la SAP de Barcelona ${ }^{60}$ se establece:

generales se ha dicho que esta garantía consiste en: a) que el demandado haya tenido debida noticia, la que puede ser actual o implícita; b) que se le haya dado una razonable oportunidad de comparecer y exponer sus derechos, incluso el de declarar por sí mismo, presentar testigos, presentar documentos relevantes y otras pruebas; c) que el tribunal ante el cual los derechos son cuestionados esté constituido de tal manera que dé una seguridad razonable de su honestidad e imparcialidad; d) que sea un tribunal competente. Esta enumeración atañe al demandado; es lo que se ha mencionado con la denominación genérica de tener derecho a estar un día ante el tribunal. Pero las garantías constitucionales del proceso alcanzan también al actor, que puede ser privado por ley de su derecho a reclamar judicialmente lo que es suyo en forma irrazonable; a los jueces que pueden ver afectadas en la ley las garantías de su investidura; a los testigos y peritos, a quienes pueden vulnerarse derechos humanos; etc."

58 LORCA NAVARRTE, A.M., ¿Tienen que ser las Instituciones Arbitrales Independientes y/o Imparciales? en Revista Vasca de Derecho Procesal y Arbitraje, Tomo XVIII, Septiembre 2006, p. 440.

59 MATHEUS LÓPEZ, C. A., "La Independencia e Imparcialidad del árbitro", ed. Instituto Vasco de Derecho Procesal, 2009, San Sebastián, p. 239.

60 Fundamentos Primero y Segundo de la SAP de Barcelona de fecha 3 de octubre de 2.003, siendo ponente D. Rosa Ma Agullo Berenguer. 
"PRIMERO.- La parte recurrente impugna el laudo solicitando su nulidad al amparo del artículo 45 de la Ley de Arbitraje por varios motivos que fueron expuestos unos en el escrito inicial de impugnación y otros en el acto de la vista al haber tenido conocimiento tras la interposición del recurso de nuevos hechos susceptibles de integrar nuevos motivos de nulidad como se expondrá más adelante. En resumen se alega por la parte recurrente que el laudo de 16 de abril de 2002 dictado por la compañía mercantil "ASOCIACIÓN EUROPEA DE ARBITRAJE DE DERECHO Y EQUIDAD” (A.E.A.D.E.) siendo árbitro la letrada $\mathrm{D}^{\mathrm{a}}$. Cristina Bellver Girona, que es origen de estas actuaciones, es nulo por no haberse observado en el nombramiento del árbitro y desarrollo del procedimiento arbitral las formalidades y principios esenciales exigidos por la Ley. Concretándose en el acto de la vista los motivos a la impugnación del convenio de sometimiento a arbitraje porque en el mismo no se daba la posibilidad de intervención en la designación del árbitro al consumidor, porque la designada como tal es letrada de la parte adversa y por ende interesada en la resolución con lo que carece de imparcialidad y objetividad para dictar el laudo; en el convenio no de designó el objeto del arbitraje ni consta aceptada la cláusula arbitral ni expresa ni tácitamente; y, por último porque en el convenio se incluye una reserva ilegal a favor de la propia asociación arbitral de ejecutar por si directamente el laudo. La parte recurrida se opuso al recurso alegando que la invocada "contaminación" del árbitro es una cuestión nueva y que el hecho de que la letrada que emitió el laudo figure ahora en el poder acompañado al escrito de contestación del recurso de nulidad de PARLA BROKER S.L. no significa que esta letrada haya actuado en este recurso y además es de fecha posterior a la emisión del laudo; oponiéndose al resto de los motivos alegando que el nombramiento de árbitro se hizo con plena notificación a las partes, se siguió un procedimiento contradictorio y de igualdad en la práctica de las pruebas.

SEGUNDO.- Se ha de rechazar la oposición de la parte recurrida en cuanto a que las alegaciones vertidas de adverso constituyen una cuestión nueva porque no ha sido sino después de la interposición del recurso cuando la parte recurrente ha tenido oportunidad de conocer la causa de abstención y/o recusación de la árbitro Sra. Bellver quien evidentemente tiene relación directa con la adversa y pese a ello actuó como árbitro de la A.E.A.D.E lo que pone en cuestión su objetividad. Pero es que, independientemente de que el recurrente alegara o no motivos nuevos en el acto de la vista, dado que los tribunales de justicia han de examinar de oficio el acatamiento de la normativa sobre protección de los derechos de los consumidores y usuarios, según jurisprudencia comunitaria (Ss. 27-6-2000; 21-11-2002) como también si se vulnera con el convenio arbitral o durante el desarrollo del procedimiento los derechos fundamentales puesto que la renuncia a la jurisdicción ordinaria que supone el sometimiento a la decisión arbitral no supone renuncia al derecho a la tutela judicial efectiva, esta sala ha de examinar de oficio la legalidad del convenio arbitral que necesariamente ha de acompañar a la petición de resolución arbitral de un determinado conflicto". 
Esa IIAA, la Asociación Europea de Arbitraje de Derecho y Equidad (AEADE), nombra a los árbitros teniendo la duda sobre si éstos, a su vez, son sus empleados ¿por qué? ¿Acaso se busca que las pretensiones de su cliente (la parte demandante en el procedimiento arbitral) se vean satisfechas? Una manera de conseguirlo sería que sus empleados dicten esos laudos. Aquí es importante también analizar el problema de inamovilidad de los árbitros.

La IA debe ser independiente respecto del asesoramiento previo de una de las partes, respecto de la no averiguación de los bienes patrimoniales del contrario, a la hora de administrar el procedimiento arbitral y designar los árbitros y, respecto de la no ejecución del laudo que dictan los árbitros. Todo ello cuando tiene un interés evidente en el objeto de la controversia, al haber elaborado ella misma los contratos.

En cuanto a la imparcialidad de la institución arbitral LORCA NAVERRETE ${ }^{61}$ se pronuncia de forma tajante: "La institución arbitral no tiene que ser imparcial, ni subjetiva, ni objetivamente (...) conceptualmente no puede ser imparcial por cuanto esos cometidos de la institución arbitral en modo alguno pueden comprometer el resultado final del laudo arbitral en la medida en que quien procede a laudar es el árbitro y no la institución arbitral. Si el árbitro designado por la institución arbitral no es imparcial no lo será porque la institución arbitral no haya sido imparcial sino porque no ha actuado independiente (...)"

$\mathrm{Y}$ añade, al hilo de los pronunciamientos dados por algunos magistrados de los procesos arbitrales respecto a este punto (que analizamos en los epígrafes anteriores): “(...) el estudio realizado (...) revienta de estupor a quien se acerque a su doctrina jurisprudencial”.

Pues bien, dicho esto reconocemos que nos acercamos y estamos de acuerdo con esta doctrina jurisprudencial, por lo tanto, afirmamos que toda IA debe ser imparcial.

Debemos empezar por ver ¿cuáles son las funciones de una IA? Dice Fernández Rozas $^{62}$ : "la entidad se limita a prestar tareas de apoyo a las partes y a los árbitros, pero no participa en la decisión del caso".

Lo primero es decir que, aunque en teoría una IA no puede participar en la decisión de la controversia que se lleva al arbitraje, en la práctica ya vimos que sí participa y de qué manera lo hace. Una vez dicho esto, y siguiendo la descripción que hace Jové Pons ${ }^{63}$ : "recibir y tramitar escritos y documentos entregados por las

${ }_{61}$ LORCA NAVARRETE, A.M., “ ¿Tienen que ser las Instituciones Arbitrales Independientes y/o Imparciales?" En: Revista Vasca de Derecho Procesal y Arbitraje, Tomo XVIII, septiembre 2006, p. 440.

62 FERNÁNDEZ ROZAS, J. C., "Luces y Sombras del Arbitraje Institucional en los litigios transnacionales" en Revista de la Corte Española de Arbitraje, vol. XXIII, 2008, p. 75.

63 JOVÉ PONS, M. A., "El Arbitraje Institucional: Las Instituciones Arbitrales" en revista Economist E Iuris, julio/agosto, 1997 p. 71. 
partes y los árbitros; informar y hacer todo tipo de notificaciones a las partes o sus abogados sobre la marcha del arbitraje; colaborar en aquellas actuaciones que requieran intervención jurisdiccional, como son la práctica de pruebas que no puedan realizar los árbitros por sí mismos, la solicitud de formación judicial, la anulación del laudo, etc.; y prestar ayuda en la protocolización del laudo.(entre otras)"

La IA realiza alguna de las funciones que, en vía judicial realizan los secretarios judiciales $^{64}$ y el cuerpo de gestión ${ }^{65}$, tramitación ${ }^{66}$ y auxilio procesal ${ }^{67}$ y adminis-

64 Arts. 453 y ss., de la Ley Orgánica 6/1985, de 1 de julio, del Poder Judicial: “Artículo 454.1. Los secretarios judiciales son responsables de la función de documentación que les es propia, así como de la formación de los autos y expedientes, dejando constancia de las resoluciones que dicten los jueces y magistrados, o ellos mismos cuando así lo autorice la ley.

2. Los secretarios judiciales ejercerán competencias de organización, gestión, inspección y dirección del personal en aspectos técnicos procesales, asegurando en todo caso la coordinación con los órganos de gobierno del Poder Judicial y con las comunidades autónomas con competencias transferidas.

3. Garantizarán que el reparto de asuntos se realiza de conformidad con las normas que a tal efecto aprueben las Salas de Gobierno de los Tribunales de Justicia y serán responsables del buen funcionamiento del registro de recepción de documentos, expidiendo en su caso las certificaciones que en esta materia sean solicitadas por las partes.

4. Facilitarán a las partes interesadas y a cuantos manifiesten y justifiquen un interés legítimo y directo, la información que soliciten sobre el estado de las actuaciones judiciales no declaradas secretas ni reservadas.

5. Promoverán el empleo de los medios técnicos, audiovisuales e informáticos de documentación con que cuente la unidad donde prestan sus servicios."

65 Art. 476 de la Ley Orgánica 6/1985, de 1 de julio, del Poder Judicial: "Corresponde al Cuerpo de Gestión Procesal y Administrativa, colaborar en la actividad procesal de nivel superior, así como la realización de tareas procesales propias.

Con carácter general y bajo el principio de jerarquía, y sin perjuicio de las funciones concretas del puesto de trabajo que desempeñen, le corresponde:

Gestionar la tramitación de los procedimientos, de la que se dará cuenta al Secretario Judicial, en particular cuando determinados aspectos exijan una interpretación de ley o de normas procesales, sin perjuicio de informar al titular del órgano judicial cuando se fuera requerido para ello...."

66 Art. 477 de la Ley Orgánica 6/1985, de 1 de julio, del Poder Judicial: "Corresponde con carácter general al Cuerpo de Tramitación Procesal y Administrativa la realización de cuantas actividades tengan carácter de apoyo a la gestión procesal, según el nivel de especialización del puesto desempeñado, bajo el principio de jerarquía y de conformidad con lo establecido en las relaciones de puestos de trabajo.

Sin perjuicio de las funciones concretas del puesto de trabajo que desempeñen, le corresponde: La tramitación general de los procedimientos, mediante el empleo de los medios mecánicos u ofimáticos que corresponda, para lo cual confeccionará cuantos documentos, actas, diligencias, notificaciones y otros le sean encomendados, así como copias de documentos y unión de los mismos a los expedientes.

El registro y la clasificación de la correspondencia..."

67 Art. 478 de la Ley Orgánica 6/1985, de 1 de julio, del Poder Judicial: "Corresponde al Cuerpo de Auxilio Judicial con carácter general, bajo el principio de jerarquía y de acuerdo con lo estable- 
trativo. Evidentemente las labores de estos funcionarios no se pueden trasladarse de forma literal a las tareas que realizan las personas que componen la IA, pero sí son funciones similares, por ejemplo, corresponde al secretario judicial impulsar el procedimiento. En el arbitraje institucional corresponde a la institución esa labor de impulsar el procedimiento arbitral, por ejemplo. La Ley Orgánica 6/1985, de 1 de julio, del Poder Judicial (en adelante LOPJ) establece:

"Artículo 452.1. Los secretarios judiciales desempeñarán sus funciones con
sujeción al principio de legalidad e imparcialidad en todo caso, al de auto-
nomía e independencia en el ejercicio de la fe pública judicial, así como al
de unidad de actuación y dependencia jerárquica en todas las demás que les
encomienden esta Ley y las normas de procedimiento respectivo, así como su
reglamento orgánico. Las funciones de los secretarios judiciales no serán objeto
de delegación ni de habilitación, sin perjuicio de lo establecido en el artículo
451.3."

A estos funcionarios se les exige imparcialidad en el desempeño de sus funciones, entonces ¿por qué sorprende que la jurisprudencia también le exija esa imparcialidad a las IIAA cuando comparten tareas del secretario judicial? Se le viene exigiendo a las IIAA imparcialidad objetiva, es decir, que esa institución no tenga relación con el objeto del procedimiento arbitral, que, en los ejemplos expuestos veíamos que sí tenían relación con la controversia al haber elaborado ellas mismas los contratos que luego eran objeto del litigio. Esta opinión también la comparte Ruiz Moreno ${ }^{68}$ y Gisbert Zamora ${ }^{69}$.

cido en las relaciones de puestos de trabajo, la realización de cuantas tareas tengan carácter de auxilio a la actividad de los órganos judiciales. Asimismo, y entre otras funciones, le corresponderá:

La práctica de los actos de comunicación que consistan en notificaciones, citaciones, emplazamientos y requerimientos, en la forma prevista en las leyes procesales, a cuyo efecto ostentará capacidad de certificación y dispondrá de las credenciales necesarias..."

68 RUIZ MORENO, J. M., "Nombramiento y aceptación de los árbitros. Imparcialidad, Abstención y Recusación" dentro del libro Estudios sobre el arbitraje: los temas clave, ed. La Ley, 2008, p 99: "En la citada SAP de Madrid de 28 de julio de 2005se analiza un interesante supuesto en donde la imparcialidad se hace sentir no tanto sobre la persona del árbitro como sí de la institución administradora del arbitraje que se ha encargado de su nombramiento. (...) El tribunal acabó estimando el recurso de anulación del laudo por entender que la asociación administradora del arbitraje no gozaba de la imparcialidad objetiva suficiente para administrarlos."

69 GISBERT ZAMORA, M., "El Arbitraje Institucional en la Ley 60/2003 de 23 de diciembre", en Derecho de los Negocios, n' 168, septiembre de 2004, p. 16: "El deber de imparcialidad de la institución arbitral. Aunque la ley no lo establezca de forma expresa, no cabe duda de la necesidad de que la administración del arbitraje se desarrolle con total imparcialidad, porque el incumplimiento de este deber puede incluso suponer la nulidad del convenio arbitral, si los árbitros hubieran sido nombrados por la institución, art. $41.1 \mathrm{LA}$. En cuanto a la responsabilidad de la institución derivada de la actuación de los árbitros, entendemos que el 
Pero ¿con qué problemas nos encontramos? La LA guarda silencio y no regula estos puntos. A su vez, serían las IIAA las encargadas de regular unos límites o incompatibilidades, pero es bastante difícil que una IA se establezca límites a sí misma, de hecho en los reglamentos estudiados se enuncian normas deontológicas pero todas ellas encaminadas al árbitro, no a las IIAA. Por eso, somos partidarios de que el legislador regule las incompatibilidades de estas instituciones, así como un régimen sancionador.

\section{3 ¿Debe abstenerse de administrar un procedimiento arbitral la institución arbitral y se puede recusar la misma?}

Lorca Navarrete ${ }^{70}$ contesta: “(...) la institución arbitral ni se puede abstener ni se puede recusar (...)".

La LA no regula nada al respecto, como ya venimos diciendo, por lo que hay un vacío en este punto. Si partimos de que la IA debe ser imparcial, a su vez, es necesario establecer unas causas de incompatibilidades que tendrá que observar esa institución, y, como consecuencia, la IA no debe administrar aquellos procedimientos arbitrales en los que se encuentren incursas esas incompatibilidades. Pero ¿cuál es el problema que nos surge? Que ni en la LA, ni en los reglamentos arbitrales españoles se establecen ni las incompatibilidades de las IIAA, ni el procedimiento a seguir cuando se den causas evidentes de imparcialidad. Situación que debe ser reparada para que las partes puedan manifestar las incompatibilidades que conocen respecto de la IA con el objeto del procedimiento arbitral.

\section{4. ¿NECESIDAD DE UNAS NORMAS DE CONDUCTA O DEONTOLÓGICAS?}

Desde la publicación de la ley 36/1988, primera norma que reconoce en nuestro país a estas instituciones arbitrales publicada el 7 de diciembre en el BOE, pasando por la ley 60/2003 hasta los días de hoy con modificación a través de la ley 11/2011, de 20 de mayo, de reforma de la ley 60/2003, de 23 de diciembre, de Arbitraje y de regulación del arbitraje institucional en la Administración General del Estado., hace ya más de veinte años, no se elaboró un código deontológico que regule de forma única, las instituciones arbitrales en España. Desde el punto de vista del interés general, y debido a la globalización, es necesario que se elaboren unas normas

legislador e incluso las instituciones deberían haber establecido los motivos concretos por los que ésta tenga que responder. De tal forma que la responsabilidad dependa de las causas que la generaron."

70 LORCA NAVARRETE, A.M., “¿Tienen que ser las Instituciones Arbitrales Independientes y/o Imparciales?" En: Revista Vasca de Derecho Procesal y Arbitraje, Tomo XVIII, septiembre 2006, p. 440. 
deontológicas vinculantes y uniformes para todos los países, por lo menos, en el ámbito europeo.

Creo necesario que se definan unos criterios, valores y límites incompatibilidades, etc., (a las que la LA no llegó) creando una norma aplicable a todas las instituciones arbitrales y a los árbitros. Y desde luego, esta norma no debe ser elaborada por las propias IIAA, ni se debe dejar en manos de códigos deontológicos, pues pueden caer en el tópico general de que las normas deontológicas: "no siempre se cumplen, aunque sí se respetan”. Por ello, sería necesario que el Estado legislador elaborase y regulase una norma de conducta o deontológica vinculante para todas aquellas instituciones que quieran administrar arbitraje y también para aquellas personas que deseen ser árbitros. Pero no como mera declaración de intenciones, sino una norma de obligado cumplimiento, reconocida como indispensable para el buen funcionamiento del arbitraje sin que se menoscaben garantías fundamentales.

Pensamos en una ley que regule los derechos, las obligaciones, las incompatibilidades y las responsabilidades tanto de los árbitros como de las instituciones arbitrales. También se debiera establecer un régimen sancionador ${ }^{71}$ para aquellos casos en los cuales, el árbitro y la institución arbitral vulneren los principios fundamentales y con ello desvirtúen y pongan en peligro tanto al arbitraje como los derechos de las partes que se someten al mismo.

Es de gran importancia para el prestigio, la consolidación y el futuro del arbitraje como un mecanismo efectivo de resolución alternativa de conflictos, que haya una norma reguladora de los derechos, obligaciones, incompatibilidades, responsabilidades y sanciones a las instituciones arbitrales y a los árbitros. ¿Y por qué no únicamente regirse por códigos deontológicos? Porque los códigos deontológicos aunque van dirigidos a garantizar una buena ejecución de un profesional, tiene que mediar su aceptación a esos códigos. Nosotros queremos ir más allá.

Las primitivas agrupaciones humanas solucionaban sus conflictos mediante la imposición del más fuerte sobre el más débil, mediante el ojo por ojo, diente por diente. Cuando se sintió la necesidad de superar esta injusta forma de poner fin a los conflictos, se intentó sustituir a los interesados directos y a sus formas de venganza privada por una persona con unas características tales que la hicieran idónea para buscar la solución justa al caso concreto y que esta solución fuera aceptada, respetada y cumplida. Surge así la figura del juez. Con el arbitraje pasa lo mismo, estamos todavía en la etapa primitiva del procedimiento arbitral en la cual deben sentarse unas bases y tomar medidas para salvaguardar los derechos de tutela del debido proceso.

\footnotetext{
71 Que pueden clasificarse como leves, graves y muy graves.
} 
A día de hoy, se puede hablar de incompatibilidades ${ }^{72}$ de manera genérica cuando estamos ante situaciones de vulneraciones graves ${ }^{73}$ de la tutela judicial efectiva, pero no se tiene que quedar ahí, debe haber unas consecuencias a esas vulneraciones. Por eso proponemos la creación de un régimen sancionador, de la elaboración de unas normas que sancionen estas conductas y limiten las funciones de las IIAA. Es necesario limitar a estas instituciones y establecer una serie de incompatibilidades para el ejercicio de la administración y gestión de los procedimientos arbitrales.

\section{REFERENCIAS}

ÁlVAREZ SÁNCHEZ DE MOVELLÁN, P., La Anulación del Laudo Arbitral, ed. Comares, Granada, 1996.

CALVO SÁNCHEZ, M. C., Control de la Imparcialidad del Tribunal Constitucional, ed. Atelier, Barcelona, 2009.

CHILLÓN M. y MERINO M. Tratado de Arbitraje privado interno e internacional, España, 1991.

COUTURE, E. J., Fundamentos del derecho procesal civil, ed. Depalma Buenos Aires, 1993.

CREMADES, B. M., "El Arbitraje en el Siglo XXI", editorial La Ley: Revista Jurídica, doctrina, jurisprudencia y bibliografía, No 4, España, 1990.

DE LA OlIVA SANTOS, A. y DÍEZ-PICAZO GIMÉNEZ, I., Derecho Procesal Civil. El Proceso de Declaración. Conforme a la Ley 1/2000 de 7 de enero, de Enjuiciamiento Civil, editorial Centro de Estudios Ramón Areces, 2000, Madrid.

DÍEZ CLAVERO, J., "Tendencias del Derecho hacia el arbitraje institucional mercantil", en Revista crítica de derecho inmobiliario, № 627, 1995.

72 FERNÁNDEZ ROZAS, J. C., "Luces y Sombras del Arbitraje Institucional en los Litigios Transnacionales" en Revista de la Corte Española de Arbitraje, vol. XXIII, 2008: "Desde el punto de vista deontológico, también se producirá una incompatibilidad manifiesta cuando un miembro de una institución arbitral actúe como asesor en la redacción del documento que incorpora el convenio arbitral, puesto que puede tener interés en la validez de dicho convenio o, incluso, de forma indirecta en favorecer los intereses que, en su momento, defendió por cuenta de la parte a la que asesoró. Y la misma situación acontecerá cuando un miembro del centro arbitral intervenga durante el arbitraje como asesor de una de las partes en litigio, pues cabe la posibilidad de su participación bien en las decisiones pre arbitrales que condicionan la intervención del árbitro, o bien en el control de la actuación de los árbitros que es inherente a la administración del arbitraje."

73 ROCA AYMAR, J.L., El arbitraje en la Contratación Internacional, Esic Editorial, 1994, Madrid, p. 105: "En relación con los principios éticos y deontológicos, las instituciones arbitrales, los árbitros, los peritos y las demás personas que participan en el procedimiento deberán ser: independientes, profesionales, eficaces y prudentes." 
FERNÁNDEZ ROZAS, J. C., "Luces y sombras del arbitraje institucional en los litigios internacionales", en Revista de la Corte Española de Arbitraje, №. 2008, 2008.

GARCÍA GÓMEZ, R., "El Convenio Arbitral de Consumo. Arbitraje de Consumo y Justicia Material" dentro del libro colectivo: Estudios de Derecho y Obligaciones. Homenaje al profesor Mariano Alonso Pérez, Eugenio Llamas Pombo (Coordinador). Editorial La Ley, Madrid, 2006.

GISBERT ZAMORA, M., "El Arbitraje Institucional en la ley 60/2003 de 23 de diciembre", en Derecho de los Negocios, n 168, septiembre de 2004.

GÓMEZ DE LIAÑO, F., El Proceso Civil, editorial Forum, Oviedo, 1990.

GUTIÉRREZ SANZ, M. R., "La Independencia e Imparcialidad de los árbitros en el arbitraje de consumo" en Estudios sobre consumo, Nㅗ 55, 2000.

JIMÉNEZ ASENSIO, R., "Imparcialidad Judicial y Derecho al Juez Imparcial en la Constitución de 1978" en el libro La Imparcialidad Judicial, ed. Consejo General del Poder Judicial, Madrid, 2009.

JOVÉ PONS, M. A., "El Arbitraje Institucional (II): Las Instituciones Arbitrales", en Revista Economist \& Iuris, 1997 julio/agosto.

LA MONEDA DÍAZ, F., "La nueva ley 60/2003, de arbitraje, y su incidencia en el sistema arbitral de consumo", en Revista La Ley, 27 de mayo de 2004.

LETE ACHIRICA, J., "Artículo 14 Arbitraje Institucional", en: Comentarios prácticos a la Ley de arbitraje (director: GUILARTE GUTIÉRREZ, V. Coord. MATEO SANZ, J. B., ed. Lex Nova, Valladolid, 2004.

LINDNER, A., "Arbitraje Internacional", Revista Economist \& Jurist, № 122, 2008.

LORCA NAVARRETE, A. M., Manual de Garantías Jurisdiccionales y Procesales del Derecho, ed. Dykinson, Madrid, 1998.

LORCA NAVARRETE, A. M., "¿Tienen que ser las Instituciones Arbitrales Independientes y/o Imparciales?” en Revista Vasca de Derecho Procesal y Arbitraje, Tomo XVIII, Septiembre 2006.

MATEU PROMEIN, C., "¿Las cláusulas de arbitraje en arrendamientos urbanos son válidas?” en Revista Inmueble a fondo, n 76 noviembre, 2007.

MATHEUS LÓPEZ, C. A., La Independencia e Imparcialidad del Árbitro, editorial Instituto Vasco de Derecho Procesal, San Sebastián, 2009.

MUNNÉ CATARINA, F., La Administración del Arbitraje, editorial Aranzadi, España, 2002.

PASARO MÉNDEZ, I., "Arbitraje y Alquiler (II): El arbitraje para resolver conflictos sobre el impago de rentas y desahucio en arrendamientos de viviendas". En Pórtico Legal, diciembre de 2007. 
RAMOS MÉNDEZ, F., Derecho Procesal Civil T II, editorial Bosch, Barcelona, 1986.

ROCA AYMAR, J.L., El arbitraje en la Contratación Internacional, editorial Esic Editorial, 1994, Madrid.

ROCA MARTÍNEZ, J. M., Arbitraje e Instituciones Arbitrales, editorial Bosch, Barcelona, 1992.

RUIZ MORENO, J. M., "Nombramiento y aceptación de los árbitros. Imparcialidad, Abstención y Recusación" dentro del libro Estudios sobre el Arbitraje: los temas clave, ed. La Ley, Las Rozas, 2008.

SAN CRISTÓBAL REALES, S., El Arbitraje de Consumo, en Anuario Jurídico y Económico Escurialense, № 40, 2007. 
